\title{
Design and Implementation of Under-forest Economic Traceability System Based on Internet of Things
}

\author{
Li Dan and Zhang Rui \\ School of Information and Computer Engineering, Northeast Forestry University, \\ Harbin, China \\ ld@nefu.edu.cn
}

\begin{abstract}
Under the background of the current food safety issues highlighted, to improve the Underforest economic product tracing efficiency, and reduce the tracking and monitoring cost, and as the under-forest economic product is sensitive to environmental parameters, this paper proposed a new method integrating RFID Barcode sensor technology to keep track of all stakes, in this process, in the traceability of storage, circulation, processing information, and the system can monitor circulation of environmental factors, such as temperature, humidity, and the paper analyzed the integrated approach of traceability system. The created system offers unique identification for under-forest product by barcode technology. And it also monitors the real-time environmental parameters of under-forest economic product by RFID (Radio Frequency Identification) electronic tag and sensor technology. The constructed system integrates the key links: the planting, processing, storage, sales, transportation and consumption of product. And it supplies enterprises, suppliers, agents and customers with under-forest product's quality traceability. In addition, this system provides a feasible scheme for exact quality traceability of under-forest economic product.
\end{abstract}

Keywords: under-forest economy; quality traceability; internet of things; barcode; RFID electronic tag

\section{Introduction}

Food sector has been affected by several food alerts and scandals in the past and even today [1-2], and food safety is one of the most focused social problems recently. The research on food safety in various professional fields is very urgent. And quality traceability system about food becomes one of research hotspots. Food traceability systems are record-keeping systems. They record product attributes, such as quality and safety parameters, required for regulatory and /or commercial purposes. It can find the source of unqualified food by tracing the food, and restrain the behavior of participants, such as producers, processors and operators [3]. So traceability system can improve the whole quality safety level of food.

Under-forest economy is a new thing in China appearing in the specific historical condition of the fundamental change of forestry development strategy and the great process of the collective forest right system reform, it is with forest planting, breeding, collection and processing of forest landscape use as the main form comprehensive of all types of industrial development and utilization of forest resources and tree-lined space and related economic activities from woodland resources understory space and forest landscape. Developing underforest economy can help to increase farmers' income, accelerate the pace of the forestry structure regulation and consolidate achievement of collective forest right system reform and ecological construction. Recently, under-forest economic product like agarics, fungus, 
blueberry and ginseng takes important position in human diet and daily health care, and their demand is becoming greater.

Traceability systems required to comply with the new food regulations can yield a huge volume of information like data collection, storage and accessibility become critical. The evolution of traceability systems has been based on the introduction of Information Technologies (IT) and Enterprise Resource Planning (ERP) in the companies [6].

Moreover, Internet of things technology like barcode, RFID etc. has developed rapidly recently. And it has been widely applied to some industries such as agriculture, forestry, communication and transportation, and catering. With the development of information technology, new technologies like 2D barcodes, RFID and WSN have been introduced into food traceability systems [4-5], In recent years, a great research interest about integrating RFID and WSN within the food supply chain has emerged, and there have been some practical implementations in companies that are now using RFID for food supply chain in Italy, France, UK, Sweden, the USA and Canada [7-10]. The quality traceability systems about beef, soybean, vegetable and fresh product have been established in China [11-13]. But the research report about the quality traceability of under-forest economic product is less.

Therefore, this paper aims at studying the key technology of internet of things for quality traceability system about under-forest economic product. It aims to contribute to the theoretical understanding of quality traceability system in two ways. First, it proposed a method integrating RFID Barcode sensor technology to keep track of all stakes, in this process, in the traceability of storage, circulation, processing information, and the system can monitor circulation of environmental factors, such as temperature, humidity. Second a new traceability system for under-forest economic is established, it provides the details about under-forest economic information for the consumers and a good operation platform management and quality safety monitoring. Application results show that the system can improve the tracing efficiency and reducing the tracking and monitoring cost.

\section{The Quality Traceability System based on Internet of Things}

Quality traceability system based on internet of things connects the chargers of product, enterprises, agents and customers, to a unified platform. And the system integrates the key links: the planting of product, processing, storage, sales, transportation, consumption etc. Barcode technology, RFID, and sensor technology can be inordinately used in the different links. The information collected and transmitted can be shared by all the participants. In this way, accuracy, reliability and transparency of the system can be clearly shown. The structure of the system can be shown in Figure 1. 


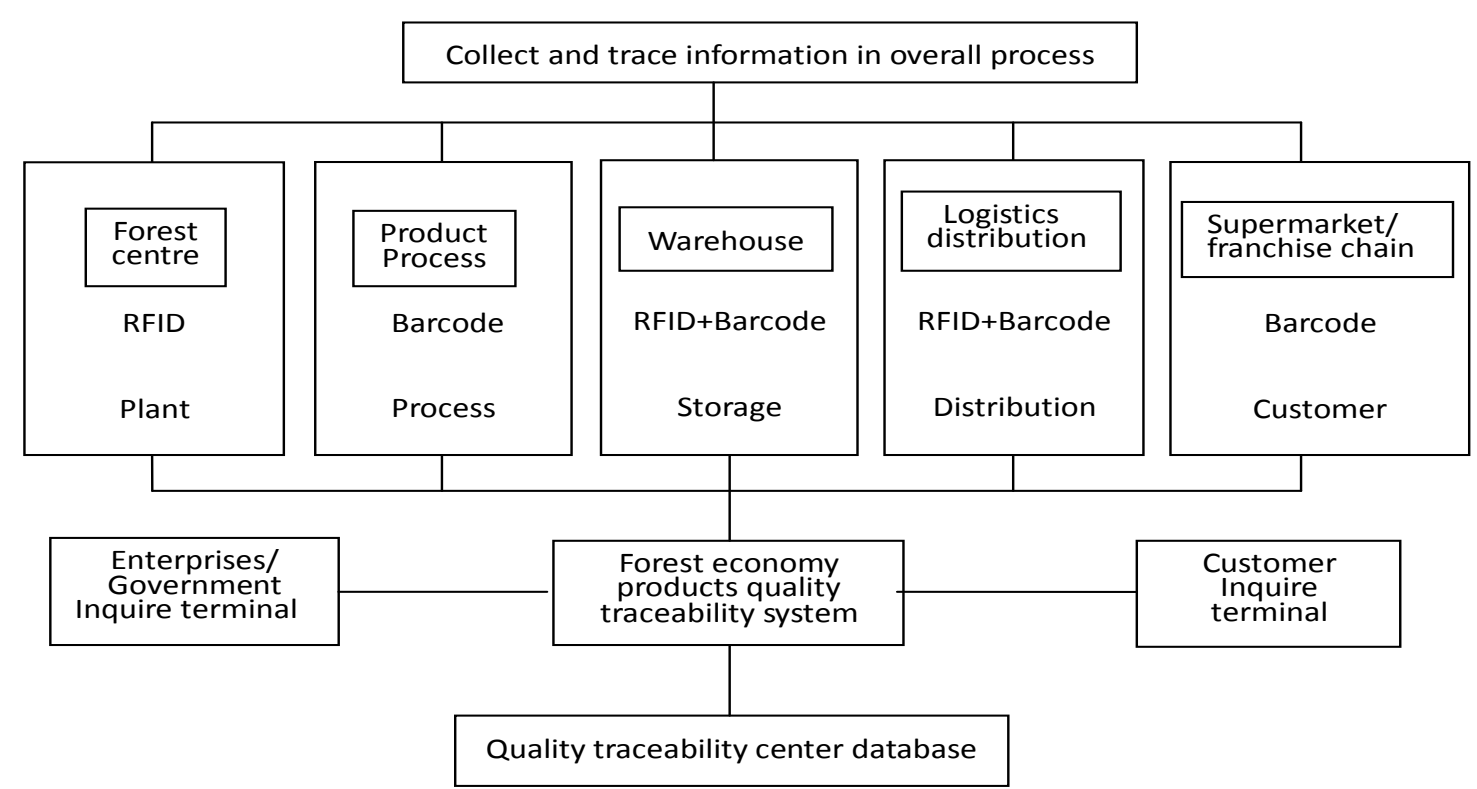

Figure 1. Quality Traceability System Based on Internet of Things

The basic principles of the quality traceability system for under-forest economic product are as follows. The system focuses on product supply chain. It regards product barcode as information delivery tool to trace product's quality. In the part of planting, RFID and sensor technology are used to supervise the environmental parameters, such as temperature and humidity etc., of the planting factory. So under-forest economic product, which is sensitive to the parameters, could grow in a friendly environment. In the part of processing, batch processing or packages can be taken as smallest independent record unit. The processing information and basic product information in the same batch or package will be recorded into barcode. In the part of storage, the barcode information on the packing-case will be read in independent package. Accurate inventory and monitoring environmental parameters in the warehouse can make sure that the product will not go bad. In the part of transportation, the barcode information will be read between receiving link and dispatching link in transportation batch. The sensor and RFID technology will be used to control the environmental parameters' reading, showing and controlling. So the product can avoid going bad in the transportation part. In the part of selling and after-sales, the product information can be distinguished through the barcode in independent package. The product information in overall process will be traced by barcode and the data in the database. The database records the information in the process of product circulation. Once the under-forest economic product that customers buy and eat is unqualified, the problems will be located exactly by tracing inquiring upwards. The enterprises manager could check the current state of the product by tracing downwards.

\section{The Application of Method Integrating Mixed Barcode and RFID Technology.}

\subsection{Barcode Technology Applied to Identification of Under-forest Product.}

The tracing code of under-forest economic product is a unique identification in the process of product circulation. And it is essential to the quality traceability system. The coding for under-forest economic product will take EAN/UCC-128 code scheme in this paper. The key 
elements, including producers (suppliers), producing area, the date of picking (purchase date), product category, and packaging date (processing date), will be chosen to design the tracing code in details. The rule of the tracing code for under-forest economic product is displayed in Figure 2.

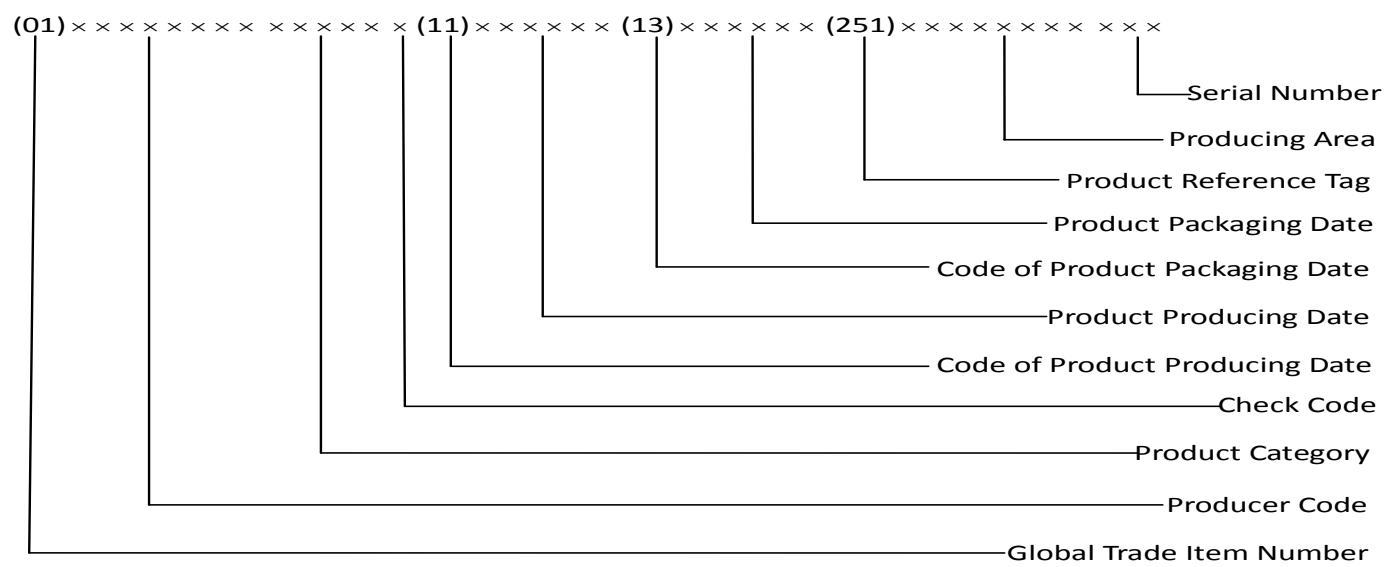

\section{Figure 2. The Coding Rules of Barcode for Under-Forest Economic Product}

The Producing Area (PA) takes 8 bits, which consists of Forestry Bureau code, forest center code, compartment code and sub-compartment code. The PA code will identify the source of some under-forest economic product. The last check code in the Global Trade Item Number (GTIN) will be determined by EAN/UCC structure standard computing method. For example, some product will be charged by a company whose code is 25312 . The product locates in Number 01 sub-compartment, Number 02 compartment, Number 10 forest center, Number 05 Forestry Bureau. On June 12, 2013, the product whose category number is 0001 would be picked, and would be packed on June 14, 2013. So the generated barcode is (01)96942531200015(11)130612(13)130614(251) 05100201012, as is shown in Figure 3 after output.

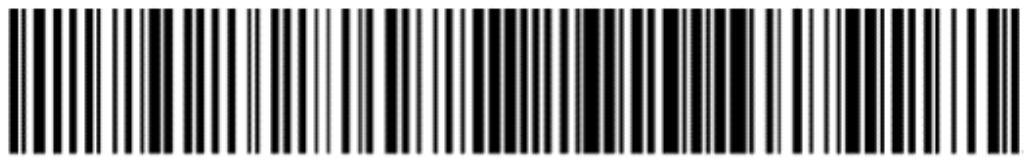

(01) 96942818902001 (11)090602 (13)090603 (251)A0001

Figure 3. The Example of Barcode Generated

When distributing barcode, different barcodes will be used according to the size of product and processing unit or the objects of responsibility area. Make sure that different barcode of object will not be mixed. Meanwhile, separating the same objects before packing and selling should be avoided. Because the mixed objects will lead to separating the barcode and product, the previous links will not be traced. Besides, if the objects were early separated, the tracing record of the subsequent links would be distributed new barcodes. The generated barcode will be pasted on the package; in the part of storage, selling, transportation and distribution, the product will be uniquely distinguished through scanning the barcode. And other relevant information will be got by connecting the database center, so the product will be traced. 


\subsection{The Integration of RFID and Sensor Technology}

Under-forest economic product is sensitive to environmental parameters, such as temperature and humidity, in the part of planting, storage and transportation. To ensure the quality of the product, the temperature and humidity information must be exactly monitored in real time. Considering the convenience and low cost of implementing supervision, this paper combines two kinds of approaches: one method is that sensor will be added into RFID tag; the other is that RFID reader and writer will add sensor [14]. Collecting and monitoring the temperature and humidity of under-forest economic product needs three devices. The first device calls JRFW-2-11(900M) temperature data collecting card. The second one calls JRFW-2-21(900M) humiture capture terminal. The last is JRFR-2-21 (900M) humiture recorder of wireless receiving end. In the process of measuring the humiture data, the inner humiture measuring components of these devices produce the humiture signal, and the output of the signal takes on certain nonlinear characteristics, and so the practical measured data from these devices need converting to acquire the real humiture information. The conversion formula of relative humiture data is as follow:

$$
R H_{\text {linear }}=C_{1}+C_{2} \times S O_{R H}+C_{3} \times S O_{R H}^{2}
$$

\section{Table 1. The Conversion Ratio of Humidity}

\begin{tabular}{cccc}
\hline $\mathrm{SO}_{\mathrm{RH}}$ & $\mathrm{C}_{1}$ & $\mathrm{C}_{2}$ & $\mathrm{C}_{3}$ \\
\hline 12 bit & -4 & 0.0405 & $-2.8^{*} 10^{-6}$ \\
8 bit & -4 & 0.6480 & $-7.2^{*} 10^{-4}$ \\
\hline
\end{tabular}

In Table 1, SORH is output value of relative humidity from practical measuring. The formula is used to make up for the nonlinear characters of sensor to acquire accurate data and correct the output value. So if the difference between the measured temperature and $25^{\circ} \mathrm{C}$ is very large, the temperature correction factor of humidity sensor must be considered. The correction formula is as follow:

$$
R H_{\text {true }}=\left(T_{{ }^{\circ} \mathrm{C}}-25\right) \times\left(T_{1}+T_{2} \times S O_{R H}\right)+R H_{\text {linear }}
$$

$T_{{ }^{\circ} \mathrm{C}}$ is the current temperature value. The compensation ratio of temperature is shown in Table 2.

Table 2. The Compensation Ratio of Temperature

\begin{tabular}{ccc}
\hline $\mathrm{SO}_{\mathrm{RH}}$ & $\mathrm{T}_{1}$ & $\mathrm{~T}_{2}$ \\
\hline 12 bit & 0.01 & 0.00008 \\
8 bit & 0.01 & 0.00128 \\
\hline
\end{tabular}

In the same way, to obtain accurate temperature data, the practical measured temperature needs to be corrected to some extent. The formula is as follow:

$$
\text { Temperatur } \quad e=D_{1}+D_{2} \times S O_{T}
$$


$\mathrm{SO}_{\mathrm{T}}$ is the measured temperature value. The values of the parameters $\mathrm{D}_{1}$ and $\mathrm{D}_{2}$ are measured under $3.3 \mathrm{~V}$ voltage supply in Table 3 .

Table 3. The Conversion of Temperature

\begin{tabular}{rcc}
\hline $\mathrm{SO}_{\mathrm{T}}$ & $\mathrm{D}_{1}\left[{ }^{\circ} \mathrm{C}\right]$ & $\mathrm{D}_{2}\left[{ }^{\circ} \mathrm{C}\right]$ \\
\hline 14bit & -39.60 & 0.01 \\
12bit & -39.60 & 0.04 \\
\hline
\end{tabular}

\subsubsection{The Selection of Device for Information Collecting}

(1) JRFW-2-11(900M) temperature data collecting card

This temperature tag integrates RFID and real-time temperature measurement technology. The device could recognize the product through the 64 bits ID number automatically; and could measure environmental temperature of the product periodically. Besides, the real-time temperature value could be extracted by receiver in way of wireless. So the temperature could be monitored and controlled in the overall process. Therefore, the environmental temperature whether it exceeds the permissible value could be intuitively judged. This device belongs to active tags; its battery life is between 1 and 3 year. The communication distance will reach $100 \mathrm{~m}$. The precision of measuring temperature is among 0.5 degree range of error. The interval time for data collecting is between 30 seconds and 1 hour; and this could be set according to the need, as shown in Figure 4.

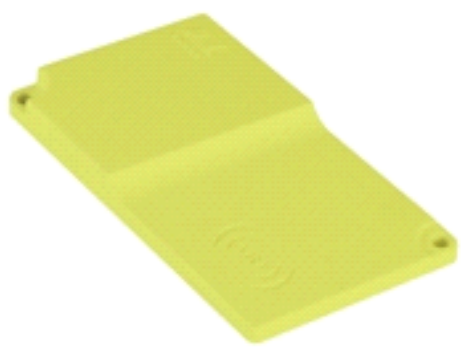

Figure 4. Jrfw-2-11(900m) Temperature Data Collecting Card

(2) JRFW-2-21(900M) humiture capture terminal

This capture terminal adopts sensor transmitter integrated and dedicated circuit. This device has characteristics of reliable performance, instant reaction and wide measurable distance. It has priorities in cost and accuracy compared with the similar product. And it uses its own protocols; there is no need for parameters' configuration. More importantly, cumbersome wiring processes will not be needed. Its battery life is between 1 and 3 year. The communication distance will reach $600 \mathrm{~m}$. The precision of measuring temperature is within the error range of 0.5 degree and the precision of humidity is within the error range of $3 \%$. The interval time for data collecting is between 30 seconds and 12 hours. The communication distance and the interval time for data collecting could be set according to the need, as shown in Figure 5. 


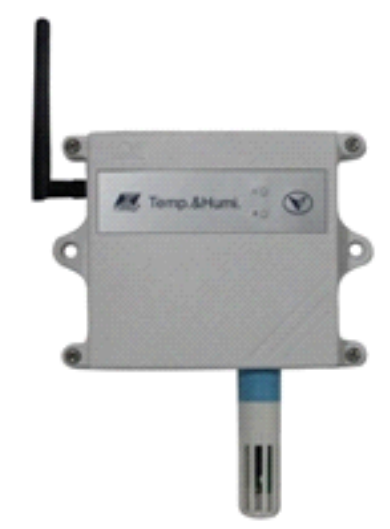

Figure 5. JRFW-2-21(900M) Humiture Capture Terminal

(3) JRFR-2-21 (900M) humiture recorder of wireless receiving end

With the use of this recorder and active capture terminal, the reading of data and configuration can be done directly. This recorder has SD card storage so as to save the collected data. Meanwhile, it has the function of upper and lower limits alarm for temperature and humidity. And LED could show the alarm. The collected data could be saved as TXT file format according to certain rules. It could collect data from 200 capture terminals. Its max communication distance could reach $400 \mathrm{~m}$. Address allocation of capture terminal will be exempted; so the data interference of capture terminal from the outside network-side will be prevented. Figure 6 illustrates the picture of the device.

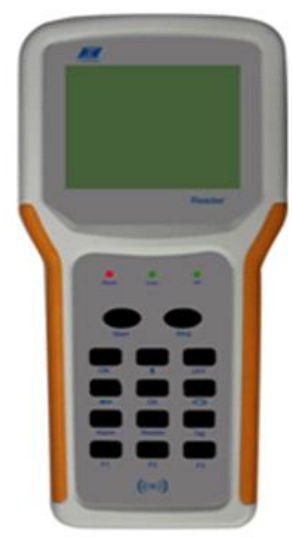

Figure 6. JRFR-2-21 (900M) Wireless Receiving End Humiture Recorder

\subsubsection{Scheme Implementation and Principles of Information Collecting}

Specific scheme could be drafted according to the above chosen devices. To begin with, the temperature label whose parameters have been set affixes to the product packaging. Secondly, the humiture capture terminal should be placed in product storage area. In the part 
of storage and transportation, data of temperature and humidity could be captured by the capture terminal; and the data will be stored into SD card. The stored data in SD card could be read to record and monitor the product in real time. Meanwhile, humiture data format will be converted to trace the product later, as shown in Figure 7.

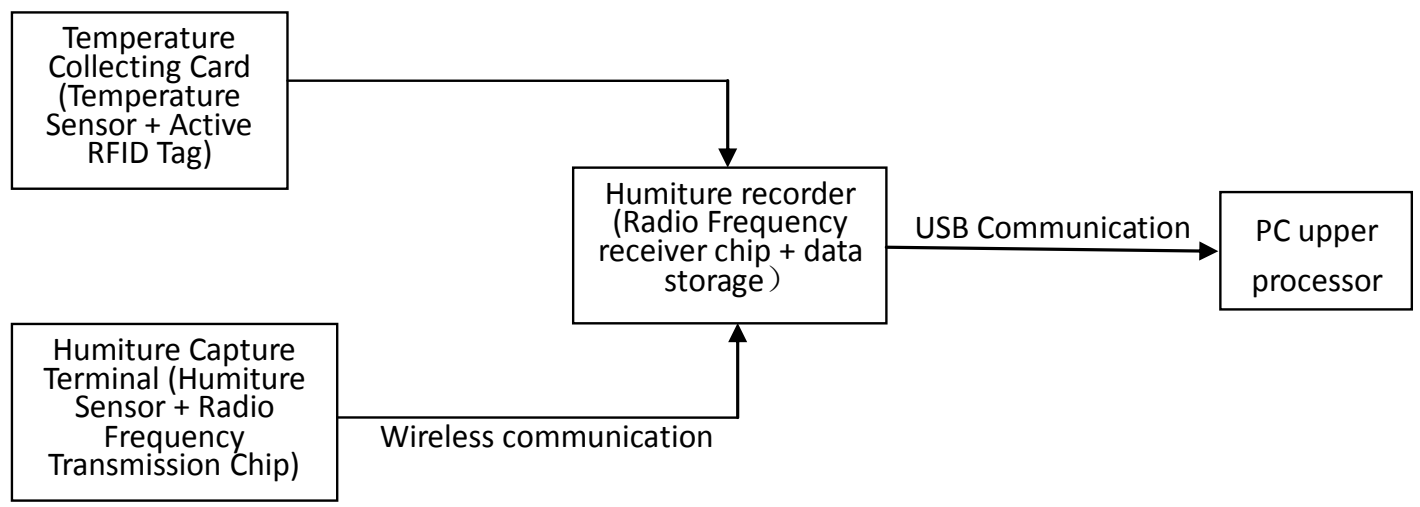

\section{Figure 7. The Relation of Devices about Humiture Information Monitoring}

One or more electronic tags and humiture capture terminal should be dispersedly placed in the container, as shown in fig.8. Transport personnel handholds the humiture recorder and uses the three devices to collect the information of temperature and humidity. The steps are as follows.
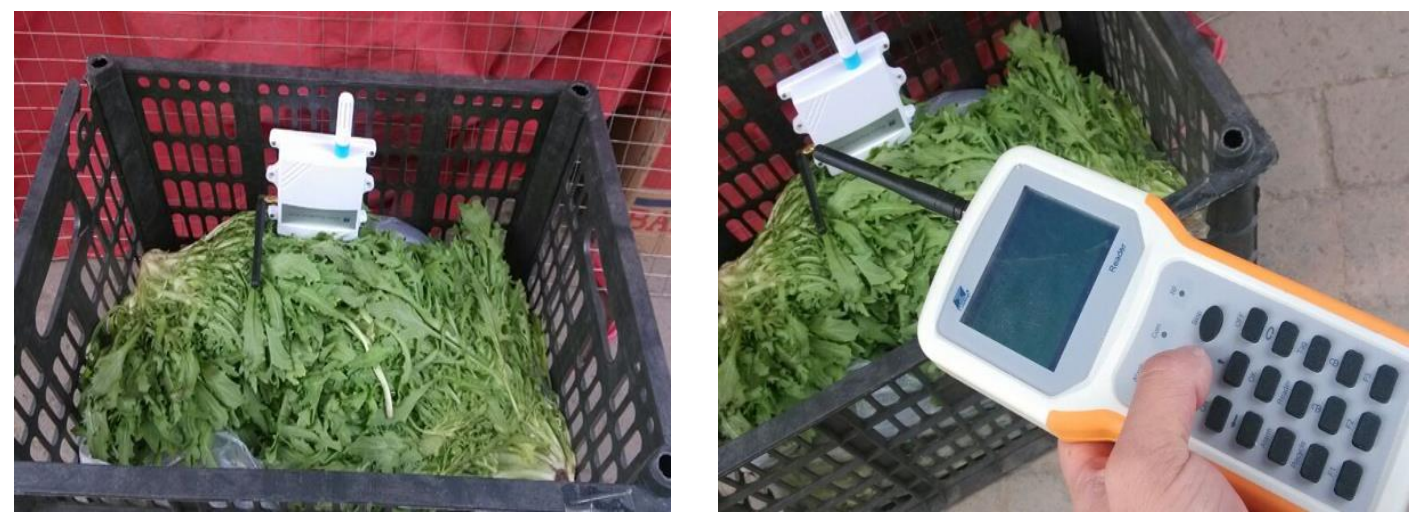

Figure 8. The Individual RFID and Receiving Recorder Put in the Holding Room

(1)Set the time interval for data collecting, the default time interval is between 2 seconds and 2 minutes. To make sure the under-forest economic product could be monitored in real time.

(2)Set the system boot time, the time should be 10 minutes later than the system clock. To ensure the collected data from temperature tags and humiture capture terminal is valid.

(3)Send start command, start to capture and receive the data.

After the transporter sends out the start command, RFID temperature tag and humiture capture terminal step into running state. The upper processor sets a fixed interval for updating information. When the fixed interval is near, the upper processor will remind the transporter to finish the data collecting process. The transporter sends out the end command; the 
collected humiture data will be stored into TXT file in a fixed format. The upper processor will connect the handheld recorder through USB serial connections. When the TXT file is created, the process will read the file automatically. The data information in the TXT file will be read line by line and be converted. And the converted information will be inserted into the relevant product table in the database; quality traceability about under-forest economic product could be done through the data in the database in the future. Meanwhile, the upper processor will present the collected data to the transporter in a way of dynamic curve. So the transporter could observe the monitored value of humiture and its variation trend in the container; and find the problems quickly. On March 26, 2013, an experiment was conducted in the lab. The experiment took two JRFW-2-11(900M) temperature data collecting cards, one JRFW-2-21(900M) humiture capture terminal and one JRFR-2-21 (900M) humiture recorder of wireless receiving end. The collecting time is 8 minutes. The experimental data is shown in Table 4. The address of device's information collecting is automatically allocated by handheld recorder. ID stands for the device's own code. The type of tag determines the type of device (001 stands RFID temperature tag, 002 stands for humiture capture terminal).

Table 4. The Experimental Data of Collecting Temperature and Humidity

\begin{tabular}{|c|c|c|c|c|c|}
\hline Address & ID & $\begin{array}{l}\text { Tag } \\
\text { type }\end{array}$ & Capture time & $\begin{array}{c}\text { Temperature } \\
\left({ }^{\circ} \mathrm{C}\right)\end{array}$ & $\begin{array}{l}\text { Humidity } \\
(\%)\end{array}$ \\
\hline 001 & 011F 0001 1B01 0002 & 001 & 2013-09-02 15:08:45 & 26.5 & 52.7 \\
\hline 002 & $011 \mathrm{~F} 0001$ 1B01 0001 & 001 & 2013-09-02 15:08:47 & 26.7 & \\
\hline 001 & $011 \mathrm{~F} 0001$ 1B01 0002 & 001 & 2013-09-02 15:09:45 & 26.3 & \\
\hline 002 & 011F 0001 1B01 0001 & 001 & 2013-09-02 15:09:48 & 26.4 & \\
\hline 003 & 011F 0100 1ABF 00D3 & 002 & 2013-09-02 15:10:11 & 25.8 & 52.7 \\
\hline 001 & $011 \mathrm{~F} 0001$ 1B01 0002 & 001 & 2013-09-02 15:10:45 & 25.1 & \\
\hline 002 & $011 \mathrm{~F} 0001$ 1B01 0001 & 001 & 2013-09-02 15:10:48 & 26.4 & \\
\hline 001 & 011F 0001 1B01 0002 & 001 & 2013-09-02 15:11:44 & 24.5 & \\
\hline 002 & 011F 0001 1B01 0001 & 001 & 2013-09-02 15:11:46 & 25.2 & \\
\hline 003 & 011F $01001 \mathrm{ABF} 00 \mathrm{D} 3$ & 002 & 2013-09-02 15:12:01 & 25.8 & 52.7 \\
\hline 001 & 011F 0001 1B01 0002 & 001 & 2013-09-02 15:12:44 & 26.7 & \\
\hline 002 & 011F 0001 1B01 0001 & 001 & 2013-09-02 15:12:46 & 27.1 & \\
\hline 001 & $011 \mathrm{~F} 0001$ 1B01 0002 & 001 & 2013-09-02 15:13:44 & 28.5 & \\
\hline 002 & 011F 0001 1B01 0001 & 001 & 2013-09-02 15:13:46 & 27.1 & \\
\hline 003 & 011F $01001 \mathrm{ABF} 00 \mathrm{D} 3$ & 002 & 2013-09-02 15:13:56 & 26.3 & 52.9 \\
\hline 001 & 011F 0001 1B01 0002 & 001 & 2013-09-02 15:14:46 & 25.4 & \\
\hline 002 & 011F 0001 1B01 0001 & 001 & 2013-09-02 15:14:46 & 26.3 & \\
\hline 003 & 011F $01001 \mathrm{ABF} 00 \mathrm{D} 3$ & 002 & 2013-09-02 15:15:43 & 26.4 & 52.5 \\
\hline 001 & 011F 0001 1B01 0002 & 001 & 2013-09-02 15:15:46 & 27.1 & \\
\hline 002 & 011F 0001 1B01 0001 & 001 & 2013-09-02 15:15:47 & 26.8 & \\
\hline 001 & 011F 0001 1B01 0002 & 001 & 2013-09-02 15:16:44 & 26.6 & \\
\hline 002 & $011 \mathrm{~F} 0001$ 1B01 0001 & 001 & 2013-09-02 15:16:46 & 24.9 & \\
\hline
\end{tabular}

\section{The Construction of Network Platform for Under-forest Economic Product}

\subsection{The Construction of the Overall Framework}

According to the above discussion on quality traceability system of the under-forest economic product and relevant technologies, the overall framework consists of $\mathrm{C} / \mathrm{S}$ (Client/Server) and B/S (Browser/Server) model. The process of making and scanning barcode and capturing humiture information adopts the model of $\mathrm{C} / \mathrm{S}$; the product information 
inquiry of the terminal user adopts $\mathrm{B} / \mathrm{S}$ model. The overall framework of under-forest economic product quality traceability system is illustrated in the below Figure 9.

$B / S$
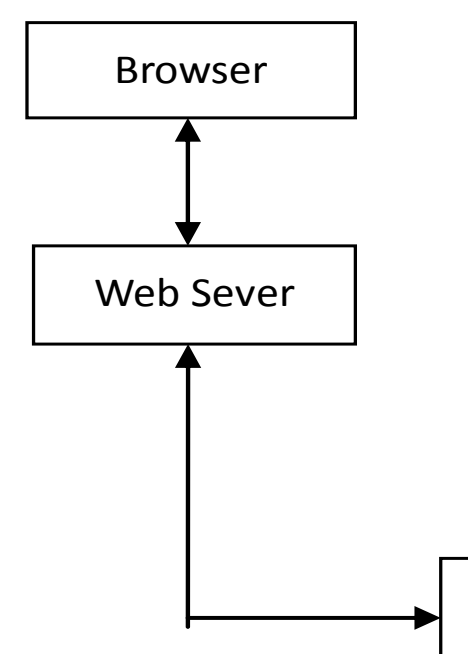

Database
$\mathrm{C} / \mathrm{S}$

Humiture Info

Capture

Barcode

Scanning

Barcode

Making

Figure 9. The Overall Framework of Quality Traceability System

\subsection{The Construction of Key Functional Modules}

After the analysis of quality traceability system for under-forest economic product, the construction of involved key functional modules could be designed. As shown in Figure 10.

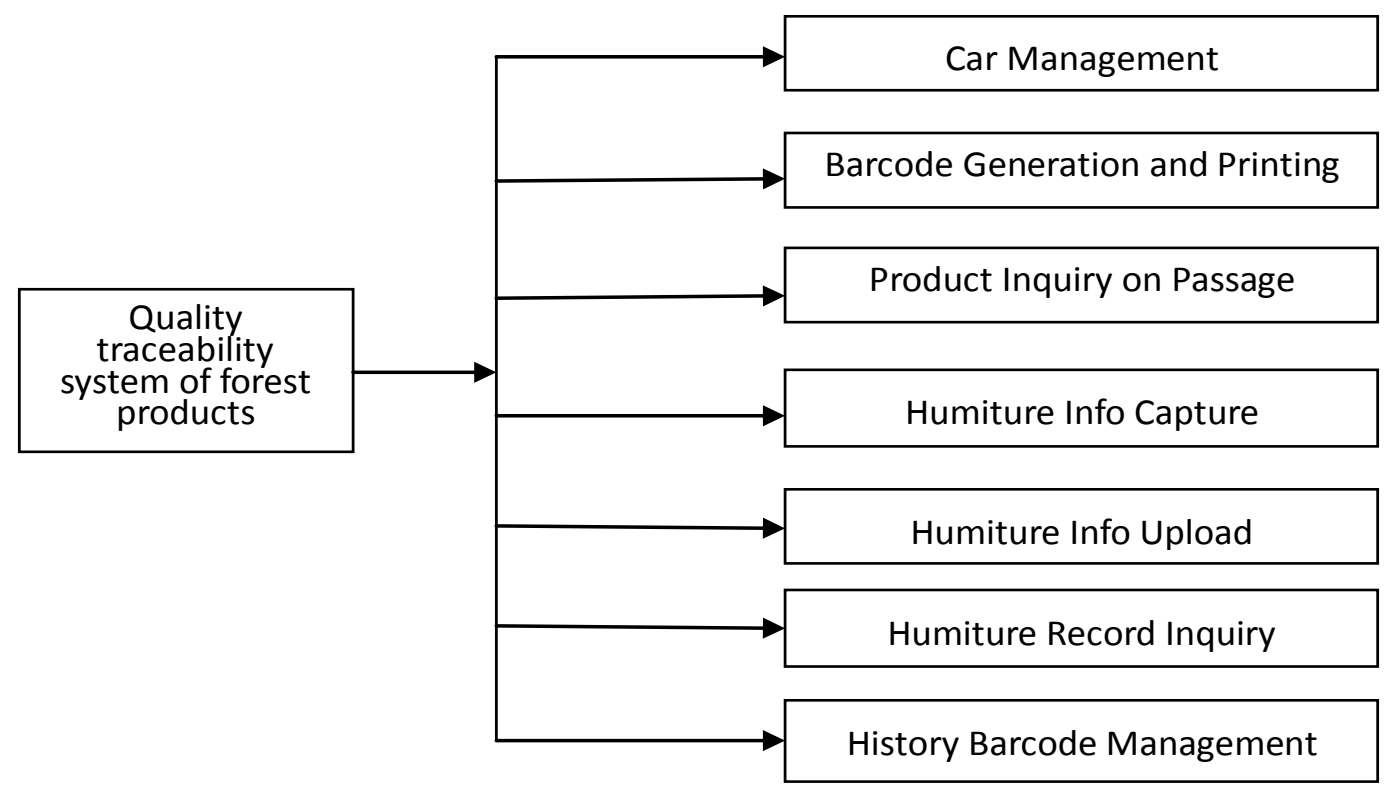

Figure 10. The Key Functional Modules For Under-Forest Economic Product Quality Traceability System 


\section{(1)Car Management}

In this module, the fundamental information, like the ownership of product transportation car, car's number and tasks, will be recorded. Once the transportation of product has problems, the main responsibility can be easily confirmed.

\section{(2)Barcode Generating and Printing}

Barcode information will be matched with the information of the current product. The barcode pattern will be generated, printed and affixed to the product packaging.

\section{(3)Product Inquiry on Passage}

The product participants, such as enterprises, middle businessmen, and customers etc., could inquire the current transportation state and history transportation tracks by orders and the product barcode. And electronic map will show those to us intuitively. So the latest information about product can be known. The tracing and tracking of the product will be possible.

\section{(4)Humiture Info Capture}

The temperature tag, humiture capture terminal and humiture recorder will be used in this module. Temperature and humidity can be captured by using these devices.

\section{(5)Humiture Info Upload}

The data information stored in SD card will be uploaded into upper processor. So PC upper processor could process the information for future use.

\section{(6)Humiture Record Inquiry}

The uploaded humiture information will be converted and curved into curve graph. The humiture information at any time will be offered by inquiry interface. So the terminal users could monitor the environmental parameters of the product on passage.

\section{(7)History Barcode Management}

The allocated barcodes will be recorded and managed in the functional module. So the non uniqueness of the barcode could be avoided. And the scale of the product could be known according to the number of the allocated barcodes.

\subsection{The Construction of Database}

According to the designed results of functional modules of quality traceability system for under-forest economic product, the structure of the tables in the database could be created. The involved database tables include: car information table, barcode table, scanning info table, product tracking table, product on passage table, product category table, humiture info table, product producing area table, and suppliers table. Due to limited space, the relation of tables and the design of table field are partly shown in the Figure 11. 


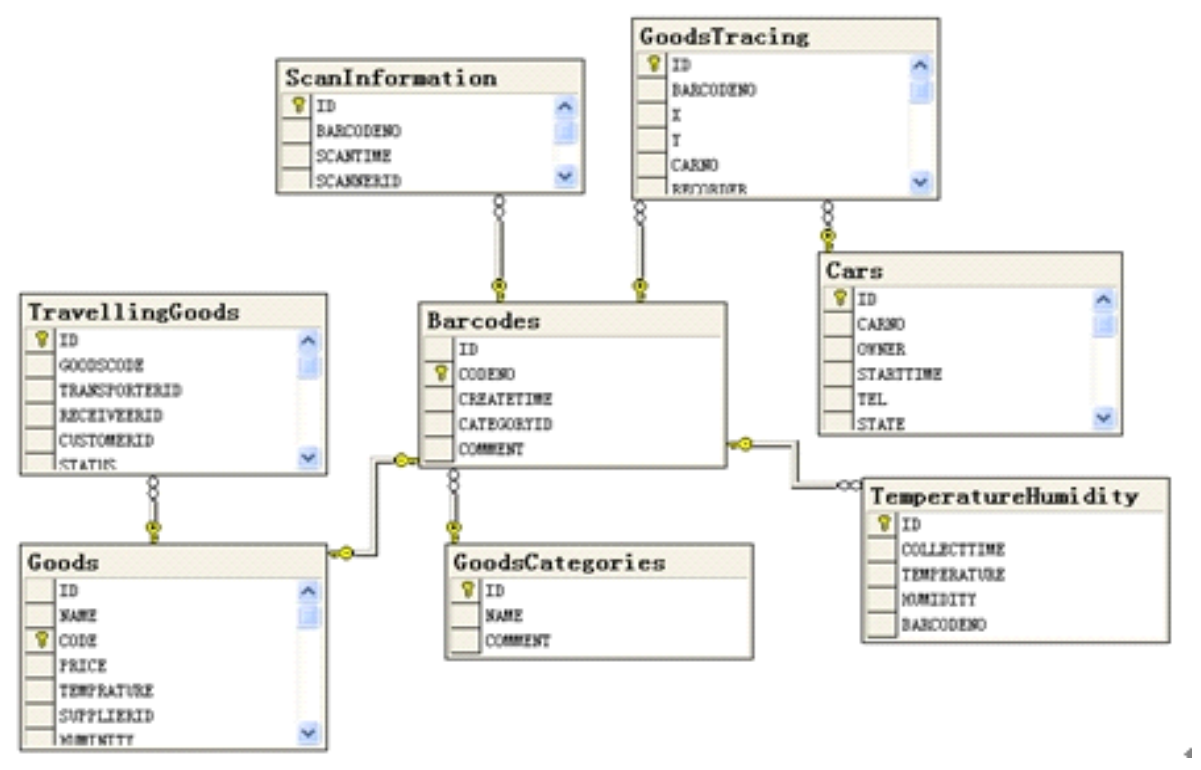

Figure 11. The Relation of Some Main Tables in Database

\subsection{The Application Example of Blueberry Quality Traceability Management}

To monitor the real-time environmental information of under-forest economic product and share the tracing data of under-forest economic product, quality traceability network system should be created. In this system, the mixed barcode and RFID technology will be used. The alarm and control management of humiture could be realized through capturing and management of one or more recognized under-forest economic product. And the relevant participants in the part of transportation share their product data information. Therefore, the quality traceability system for under-forest economic product could be established. The related technologies, JSP, Linq to SQL and FushionCharts etc., will be used to develop the system. Taking blueberry tracing as an example, the interface of the generation of barcode is shown in Figure 12; the interface of the real-time supervision of humiture information is shown in Figure 13.

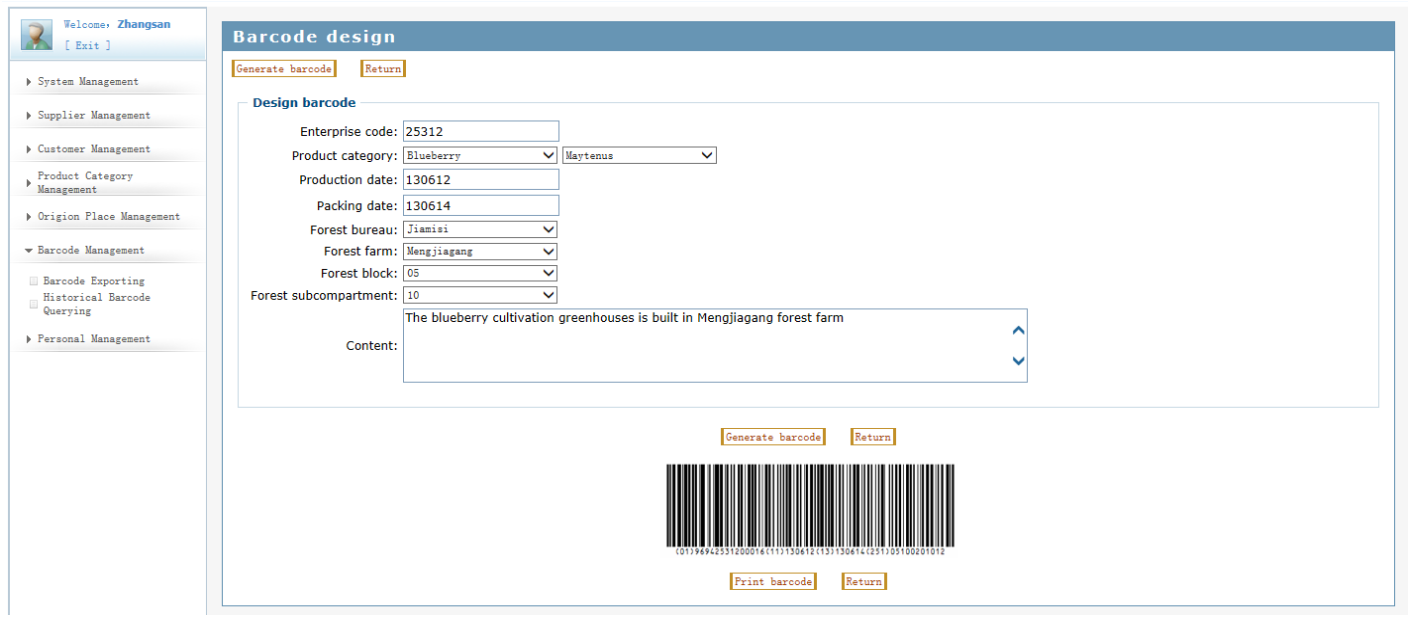

Figure 12. The Generation of Blueberry Barcode 


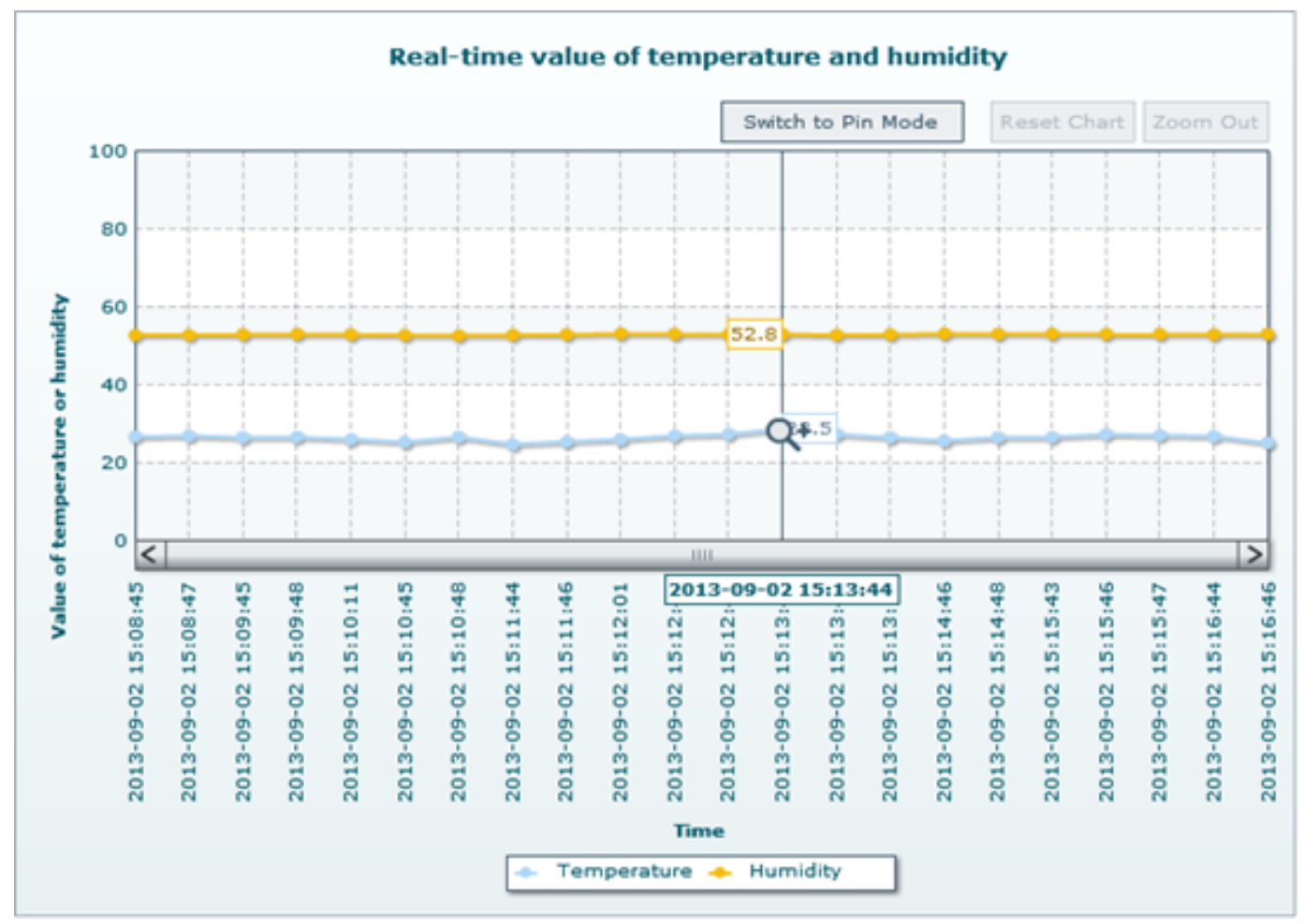

Figure 13. The Real-Time Supervision of Humiture Information

\section{Conclusion}

A feasible quality traceability system based on internet of things has been created in this paper. The relevant participants, like suppliers, producers, agents, and customers etc., could carry out the quality traceability of product in the system. The recognition of product is accomplished by barcode technology; and some barcode coding rules suitable to under-forest economic product have been designed. And the principles of the recognition and scanning of barcode have been explained in this paper. RFID electronic tags have been used to control the quality of product. The selection and scheme implementation of devices for capturing humiture information have been devised. The experimental results about the scanning and printing of barcodes and the capturing of humiture information proved the feasibility of the quality traceability system.

\section{Acknowledgements}

This work has been supported by the Fundamental Research Funds for the Central Universities Nos. 2572014CB24 and Heilongjiang Natural science fund in China Nos.F201116. 


\section{References}

[1] M. Gamberi Regattieri and R. Manzini, "Traceability of food products: general framework and experimental evidence", Journal of Food Engineering, vol. 81, no. 2, (2007), pp. 347-356.

[2] J. Storoy, M. Thakur and P. Olsen, "The Trace Food framework-principles and guidelines for implementing traceability in food value chains", Journal of Food Engineering, vol. 115, (2013), pp. 41-48.

[3] F. Moises, B. Epelbaum and M. Martinez, "The technological evolution of food traceability systems and their impact on firm sustainable performance: A RB Vapproach Int. J. Production Economics”, (2014), pp. 215-224.

[4] N. Wang, N. Zhang and M. Wang, "Wireless sensors in agriculture and food industry-recent development and future perspective", Computer and Electronics in Agriculture, vol. 50, no. 1, (2006), pp. 1-14.

[5] R. Wang, S. Prives, R. Fishcer and M. Salfer, et.al., "Data analysis and simulation of Auto-ID enabled food supply chains based on EPCIS standard", In Proceeding of the IEEE International Conference on Automation and Logistics, China, (2011), pp. 58-63.

[6] M. Bevilacqua, F. E. Ciarapica and G. Giacchetta, "Business process reengineering of a supply chain and a traceability system: a case study", Journal of Food Engineering 93, (2009), pp. 13-22.

[7] R. Angeles, "RFID technologies: supply-chain applications and implementation issues", Information Systems Management, vol. 22, no. 1, (2005), pp. 51-65.

[8] P. Jones, C. Clarke-Hill, D. Comfort and D. Hilliear, et.al., "Radio frequency identification and food retailing in the UK", British Food Journal, vol. 107, no. 6, (2005), pp. 356-360.

[9] C. Connolly, "Sensors trends in processing and packaging of foods and pharmaceuticals", Sensor Review, vol. 27, no. 2, (2007), pp. 103-108.

[10] P. Kumar, H.W. Reinitz, J. Simunovic, K.P. Sandeep, et.al., "Overview of RFID technology and its applications in the food industry”, Journal of Food Science vol. 74, (2009), pp. 101-105.

[11] L. Lei, Z. Feng, "Design and implementation of vegetable traceability system based on internet of things", Electronic Design Engineering, vol. 19, no. 7, (2011), pp. 19-22.

[12] Z. Linsen, Z. Tongchao and S. Guanglei, et al., "Design and Development of Quality Traceability Information Management System and Safety of the Beef Production's Entire Processes", Scientia Agricultura Sinica, vol. 39, no. 10, (2006), pp. 2083-2088.

[13] S. Guanglei, Z. Linsen, D. Junbiao, et al., "Implementation of beef quality and safety traceability system via internet", Transactions of the CSAE, vol. 23, no. 7, (2007), pp. 170-173.

[14] L. Zhen, N. Wang and H. Tiansheng, et al., "Design of wireless sensor network system based on in-field soil water content monitoring", Transactions of the CSAE, vol. 26, no. 2, (2010), pp. 212-217. 